\title{
Aplicação de piraclostrobina em genótipos de milho cultivados em segunda safra
}

Andreia Vanessa da Silva, Edésio Fialho Reis, Sueisla Lopes Rezende-Silva, Ederson Antonio Civardi, Antônio Paulino da Costa Netto

Universidade Federal de Goiás - UFG, Regional Jataí, GO. E-mail: sueislalopes@gmail.com

\section{Resumo}

Objetivou-se com esse estudo avaliar os efeitos fisiológicos, o controle de doenças e os efeitos nos componentes de produção, ocasionados pela aplicação do fungicida piraclostrobina, em diferentes estádios fenológicos de genótipos de milho cultivado em segunda safra, no município de Jataí-GO. Utilizou-se o delineamento de blocos ao acaso, no esquema fatorial $3 \times 4$, com quatro repetições. Os tratamentos consistiram de três genótipos de milho e quatro épocas de aplicação de piraclostrobina. Não houve interação entre genótipos e aplicações para as variáveis avaliadas. A aplicação de piraclostrobina não interfere na fisiologia, desenvolvimento e produtividade de grãos das plantas de milho cultivados em segunda safra e não houve diferença significativa no controle das doenças ferrugem polissora, mancha de cercospora, mancha de bipolares e mancha branca pela aplicação de piraclostrobina nos genótipos estudados.

Palavras-chave: estrobilurinas; redutase do nitrato; Zea mays L.

\section{Pyraclostrobin application in different corn genotypes cultivated off season}

\begin{abstract}
Objective with this study evaluate the physiological effects, disease control and effects on the production components of pyraclostrobin fungicide, applied at different phenological stages of of second crop corn genotypes, in Jataí city. In randomized blocks in a factorial design $3 \times 4$ with four replications. The treatments consisted in three corn genotypes and four periods of pyraclostrobin application. There was no interaction between genotype and applications for the variables evaluated. For the majority of the variables the only difference were between genotypes. The application of pyraclostrobin does not interfere in the physiology, development and grain production of maize plants grown in second crop and there was no significant difference in the control of polissora blight, cercospora spot, bipolaris spot stain and white stain by the application of pyraclostrobin in the genotypes studied.
\end{abstract}

Keywords: strobilurin; nitrate reductase; Zea mays L.

\section{Introdução}

Atualmente, no Brasil, a produção de milho (Zea mays L.) realizada na segunda safra está em torno de 73 milhões de toneladas, com valores superiores à produção da cultura em primeira safra (CONAB, 2019). Sob o ponto de vista epidemiológico, a extensão do cultivo do milho em segunda safra, ocasionou algumas alterações no comportamento das doenças da cultura, tornando-se favorável ao desenvolvimento de patógenos, causadores de ferrugens, manchas foliares e podridões do colmo e da espiga (KARAN; MAGALHÃES, 2014), além aumentar a sobrevivência dos patógenos no campo.

As doenças foliares provocam danos que reduzem a área foliar (MOTERLE; SANTOS, 2019), deixando a planta menos eficiente e mais vulnerável à entrada de outros patógenos, o que pode acarretar a diminuição do processo fotossintético, com consequente perdas quantitativas e qualitativas na produção de grãos (JARDINE; LACA-BUENDÍA, 2009; MOTERLE; SANTOS, 2019, ANDRZEJEWSK et al., 2020).

O uso de fungicidas do grupo químico das estrobilurinas, associado aos do grupo dos 
triazóis, tem se mostrado uma prática de manejo economicamente viável e eficiente no controle das doenças foliares, principalmente em lavouras tecnificadas e com alto potencial produtivo (JARDINE; LACA-BUENDÍA, 2009; DUARTE et al., 2009). Além do controle eficiente de doenças foliares os fungicidas do grupo das estrobilurinas são conhecidos por estimular um melhor desempenho fisiológico de plantas, promovendo uma maior atividade da enzima nitrato redutase, além de maior assimilação líquida de $\mathrm{CO}_{2}$ e eficiência de carboxilação (AMARO et al., 2018). Esses efeitos são observados em parâmetros que tem inteira relação com o aumento de produtividade, como por exemplo, prolongamento do efeito verdejante, aumento no teor de clorofila, melhora na assimilação de nitrogênio (evidenciada pela atividade da enzima redutase do nitrato), aumento na taxa fotossintética e alterações em hormônios vegetais, como etileno (KÖEHLE et al., 2002; VENÂNCIO et al., 2003; COSTA et al., 2012a; AMARO et al., 2018).

Nesse contexto, objetivou-se avaliar os efeitos fisiológicos, o controle de doenças e os efeitos nos componentes de produção ocasionados pela aplicação do fungicida piraclostrobina em diferentes estádios fenológicos de genótipos de milho, cultivado em segunda safra, no município de Jataí - GO.

\section{Material e métodos}

O experimento foi conduzido no período de março a julho de 2015, na área da fazenda experimental da Universidade Federal de Goiás Regional Jataí, Jataí - GO, localizada a $17^{\circ} 88^{\prime} \mathrm{S}$ e $51^{\circ} 71^{\prime} \mathrm{W}$, a 662,8 metros de altitude. O clima da região, segundo a classificação de Köpen é do tipo Aw, clima tropical com estação seca de inverno. A precipitação acumulada no período foi de $439,0 \mathrm{~mm}$, e a temperatura média foi de $24{ }^{\circ} \mathrm{C}$ (INMET, 2015).

O solo da área experimental é classificado como LATOSSOLO VERMELHO Distroférrico (EMBRAPA, 2009), e apresenta textura argilosa com $530 \mathrm{~g} \mathrm{dm}^{-3}$ de argila, $125 \mathrm{~g} \mathrm{dm}^{-3}$ de silte e $345 \mathrm{~g} \mathrm{dm}^{-3}$ de areia. A amostragem do solo foi realizada na camada de 0 a $20 \mathrm{~cm}$, e os resultados obtidos na análise química foram: $\mathrm{pH}\left(\mathrm{CaCl}_{2}\right): 5,3$; P mehlich1 ( $\mathrm{mg} \mathrm{dm}^{-3}$ ): 5,6; Ca, Mg, H + Al, K, CTC (cmolc $\mathrm{dm}^{-3}$ ), SB (V\%): 1,56; 0,75; 6,4; 0,26; 9,0; $28,6 \%$, respectivamente.

O delineamento experimental utilizado foi o de blocos ao acaso (DBC), em esquema fatorial $3 \times 4$, com quatro repetições. 0 primeiro fator consistiu de três genótipos de milho, e o segundo fator, quatro épocas de aplicação de piraclostrobina. Os genótipos utilizados foram o DKB 310PRO2 ${ }^{\circ}$ (Híbrido 1), LG 6036PRO2 ${ }^{\circ}$ (Híbrido 2) e AL Bandeirante (Variedade). A escolha desses genótipos se deu pela recomendação de plantio para a segunda safra na região e por possuírem diferentes níveis de vigor, tecnologia e investimento do maior para o menor respectivamente. As épocas de aplicação foram: época 1 - Testemunha (sem aplicação de piraclostrobina); época 2 - piraclostrobina aplicada em V4; época 3 - piraclostrobina aplicada em V4 e em pré-pendoamento VT; e época 4 - piraclostrobina aplicada em VT.

Para as aplicações foliares foi utilizado fungicida comercial contendo piraclostrobina (78 g i.a. ha $\left.{ }^{-1}\right)+$ epoxiconazol (48 g i.a. ha $\left.{ }^{-1}\right)$, e adicionado adjuvante do grupo químico hidrocarboneto aromático, ésteres metílicos e poliol fosfatado $(0,5 \% \mathrm{v} / \mathrm{v})$.

Para se evitar ataque de insetos e pressão de inóculo de doenças de solo durante o processo de germinação, foi realizado tratamento de sementes em todas as parcelas do ensaio utilizando um produto comercial contendo piraclostrobina + tiofanato metílico + fipronil (100 g i.a. $100 \mathrm{~kg}^{-1}$ de semente). A adubação de base consistiu-se da aplicação em sulco de plantio de $500 \mathrm{~kg} \mathrm{ha}^{-1}$ de NPK (06-18-18). A adubação de cobertura ocorreu aos 22 dias após a semeadura (DAS), em V4, aplicou-se $100 \mathrm{~kg} \mathrm{ha}^{-1}$ de nitrogênio na forma de sulfato de amônio.

O manejo de plantas invasoras em pós emergência foi realizado aos 02 DAS, utilizandose atrazina $\left(1,0 \mathrm{~kg}\right.$ i.a. ha $\left.^{-1}\right)$ e aos 50 DAS utilizando nicossulfuron (60 g i.a. ha $\left.{ }^{-1}\right)$. Aos 37 DAS aplicou-se alfacipermetrina $\left(12,75 \mathrm{~g}\right.$ i.a. ha $\left.^{-1}\right)$ e teflubenzuron $\left(12,75 \mathrm{~g}\right.$ i.a. ha $\left.{ }^{-1}\right)$ com o objetivo de controlar a lagarta-do-cartucho (Spodoptera frugiperda).

A unidade experimental constituiu-se de cinco linhas, espaçadas a $0,45 \mathrm{~m}$ entre linhas com $6 \mathrm{~m}$ de comprimento. A área útil foi constituída pelas três linhas centrais, com cinco metros de comprimento.

Para determinação da atividade da enzima redutase do nitrato, foi utilizada a metodologia proposta por Jaworski (1971), com adição de propanol (propan-1-ol), adaptada por Meguro e Magalhães (1982). Para avaliar o efeito das aplicações de piraclostrobina nos estádios de desenvolvimento V4 e VT [V4 - devido a 
determinação do potencial produtivo da cultura do milho em razão da diferenciação floral (RITCHIE et al., 1993) e VT devido a planta atingir o máximo desenvolvimento e crescimento (MAGALHÃES; DURÃES, 2006)]; foram realizadas a aplicação dos tratamentos foliares seguida das coletas do material vegetal. No terceiro dia após aplicação em V4 e no quinto dia após a aplicação em VT devido a presença de dias nublados em VT. Coletou-se sempre a última folha totalmente expandida de três plantas por parcela. As coletas foram realizadas em horário fixo (entre 9 e $10 \mathrm{~h}$ da manhã) para minimizar o efeito variável da irradiância e da temperatura ao longo do dia. Após a coleta o material foi levado imediatamente ao laboratório de Bioquímica da UFG - Regional Jataí, onde as análises foram realizadas. Os resultados obtidos dessa variável foram expressos em $\mu \mathrm{mol} \mathrm{NO} \mathrm{N}_{2} \mathrm{~g}^{-1} \mathrm{MF} \mathrm{h}^{-1}$.

$O$ índice de clorofila foi quantificado através da leitura correspondente ao teor de clorofila, utilizando o clorofilômetro modelo Falker CFL $1030^{\circ}$. As leituras ocorreram no estádio fenológico V6 (32 DAS), sendo realizadas no terço médio da última folha completamente expandida, e no estádio VT (60 DAS), realizadas no terço médio da folha-índice (oposta à espiga) de cada planta, sendo avaliadas vinte plantas por parcela.

A severidade de doenças foi verificada através da avaliação aleatória de dez plantas na parcela útil, através da escala diagramática proposta pela Agroceres (1993). As notas de severidade desta escala variam de 1 a 9 , em que $1=0 \%, 2=1,0 \%, 3=2,5 \%, 4=5,0 \%, 5=10 \%, 6=$ $25 \%, 7=50 \%, 8=75 \%$ e $9=>75 \%$ de área foliar lesionada, considerando a severidade média da doença em todas as plantas analisadas na parcela.

De acordo com a ocorrência de doenças, foram avaliadas a ferrugem polissora (Puccinia polysora), a mancha de cercospora (Cercospora zeae-maydis), a mancha de bipolaris (Bipolaris maydis) e a mancha-branca (Pantoea ananatis).

Foram realizadas oito avaliações, em intervalos de sete dias, a partir de 60 DAS. Após a obtenção dos dados, calculou-se a Área Abaixo da Curva de Progresso da Doença (AACPD), conforme Campbell e Madden (1990), a partir da equação:

AACPD $=\Sigma[((\mathrm{Yi}+\mathrm{Yi}+\mathbf{1}) / \mathbf{2}) *(\mathrm{Ti}+\mathbf{1}-\mathrm{Ti})]$

Yi: severidade da doença na época de avaliação i (i=1,...,n);

Yi+1: severidade da doença na época de avaliação i + 1;

Ti: data da avaliação inicial (i);

Ti+1: data da próxima avaliação $(i+1)$;

$\mathrm{n}=\mathrm{n}$ ㅇ de avaliações

Aos 114 DAS quantificou-se a porcentagem de folhas senescentes $(50 \%$ ou mais do limbo foliar senescente) em relação ao total de folhas.

Após a colheita, foram avaliados o número de fileiras por espiga e número de grãos por fileira, em 10 espigas por parcela. Em seguida determinou-se a massa de mil grãos (g) de acordo com as Regras para Análise de Sementes (RAS) (BRASIL, 2009), e o rendimento de grãos $\left(\mathrm{kg} \mathrm{ha}^{-1}\right)$, ambas corrigidas para $13 \%$ de umidade.

Os resultados obtidos foram submetidos à análise de variância, e as médias comparadas pelo teste de Tukey $(P \leq 0,05)$, utilizando o software SISVAR versão 5.4 (FERREIRA, 2010).

\section{Resultados e discussão}

De acordo com o resumo da análise de variância (ANAVA), não houve interação significativa entre os fatores analisados para os valores da atividade enzimática da redutase do nitrato e índice de clorofila Falker, nos estádios fenológicos V4, V6 e VT e a porcentagem de folhas senescentes. Contudo, para $\mathrm{o}$ fator genótipo, houve diferença para todas as variáveis analisadas (Tabela 1).

Todo nitrato absorvido pelas raízes das plantas deve ser reduzido a amônio, pela ação da enzima redutase do nitrato (RN), antes de ser incorporado em compostos orgânicos, por isso ela é considerada enzima chave na regulação do metabolismo do $\mathrm{N}$ em vegetais (PURCINO et al., 1994, DONATO et al., 2004; FALCÃO, 2006; AMARO, 2018). 
Tabela 1. Resumo da análise de variância, valores de $F^{(1)}$ para: blocos, genótipos (G), aplicações (A) e suas interações $(G \times A)$, para os valores de atividade enzimática da redutase do nitrato e índice de clorofila Falker (ICF), nos estádios fenológicos V4, V6 e VT e porcentagem de folhas senescentes (F.S.). Jataí -GO, 2015.

\begin{tabular}{lccccc}
\hline \multirow{2}{*}{ Tratamentos } & \multicolumn{2}{c}{$\begin{array}{c}\text { Redutase do nitrato } \\
\left(\boldsymbol{\mu m o l} \mathbf{N O}_{2}^{-} \mathbf{g}^{-1} \mathbf{M F ~ h}^{-1}\right)\end{array}$} & \multicolumn{2}{c}{ ICF } & \multirow{2}{*}{$\%$ F.S. } \\
\cline { 2 - 5 } & $\mathbf{V 4}$ & $\mathbf{V T}$ & $\mathbf{V 6}$ & $\mathbf{V T}$ & \\
\hline Blocos & $0,94^{\text {ns }}$ & $2,06^{\text {ns }}$ & $2,21^{\text {ns }}$ & $27,92^{*}$ & $2,99^{\text {ns }}$ \\
Genótipos (G) & $16,50^{*}$ & $6,10^{*}$ & $5,52^{*}$ & $13,04^{*}$ & $10,33^{*}$ \\
Aplicações (A) & $0,75^{\text {ns }}$ & $1,04^{\text {ns }}$ & $1,98^{\text {ns }}$ & $1,09^{\text {ns }}$ & $2,10^{\text {ns }}$ \\
G x A & $3,24^{\text {ns }}$ & $0,39^{\text {ns }}$ & $0,85^{\text {ns }}$ & $1,47^{\text {ns }}$ & $1,01^{\text {ns }}$ \\
\hline CV (\%) & 40,78 & 39,72 & 4,11 & 6,02 & 17,66 \\
\hline
\end{tabular}

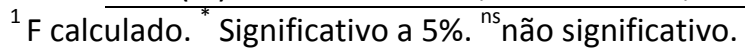

Houve diferença de comportamento entre os genótipos com relação ao estádio fenológico, para atividade enzimática da RN. Em estádio V4, o Híbrido 2 demonstrou maior eficácia em assimilar $\mathrm{N}$, enquanto que em VT, o Híbrido 1 demonstrou ser mais eficaz na assimilação de $\mathrm{N}$ e a Variedade AL Bandeirante demonstrou a menor performance nos dois estádios fenológicos com os menores valores encontrados para a atividade da enzima RN (Tabela 2).

Tabela 2. Valores médios referentes à atividade enzimática da redutase do nitrato e ao índice de clorofila Falker (ICF), nos estádios fenológicos V4, V6 e VT e porcentagem de folhas senescentes (F.S.). Jataí, GO, 2015.

\begin{tabular}{|c|c|c|c|c|c|}
\hline \multirow[t]{2}{*}{ Tratamentos } & \multicolumn{2}{|c|}{$\begin{array}{l}\text { Redutase do nitrato } \\
\left(\mu \mathrm{mol} \mathrm{NO}_{2}^{-} \mathrm{g}^{-1} \mathrm{MF} \mathrm{h}^{-1}\right)\end{array}$} & \multicolumn{2}{|c|}{ ICF } & \multirow[t]{2}{*}{ \% F.S. } \\
\hline & V4 & VT & V6 & VT & \\
\hline \multicolumn{6}{|l|}{ Genótipos (G) } \\
\hline Híbrido 1 & $1,27 b^{*}$ & 3,16 a & $50,29 a$ & $53,22 a$ & $51,79 a$ \\
\hline Híbrido 2 & $3,60 \mathrm{a}$ & $2,13 \mathrm{~b}$ & $47,0 \mathrm{~b}$ & $47,01 \mathrm{~b}$ & 49,79 a \\
\hline Variedade & $1,20 \mathrm{~b}$ & $1,88 \mathrm{~b}$ & $48,31 a b$ & $51,20 \mathrm{a}$ & $63,73 \mathrm{~b}$ \\
\hline $\mathrm{DMS}^{*}$ & 1,30 & 0,97 & 2,58 & 3,11 & 8,40 \\
\hline \multicolumn{6}{|l|}{ Aplicações (A) } \\
\hline Aplic. 1 & $2,19^{\mathrm{ns}}$ & $2,67^{\mathrm{ns}}$ & $49,11^{\text {ns }}$ & $51,89^{\text {ns }}$ & $57,77^{\text {ns }}$ \\
\hline Aplic. 2 & - & 2,67 & - & 50,10 & 50,44 \\
\hline Aplic. 3 & - & 2,13 & - & 49,38 & 52,45 \\
\hline Testemunha & 1,85 & 2,09 & 47,96 & 50,53 & 58,82 \\
\hline DMS & 0,86 & 1,24 & 1,73 & 3,97 & 10,70 \\
\hline
\end{tabular}

*Médias seguidas pela mesma letra na coluna, não diferem entre si pelo teste Tukey $(P>0,05) .{ }^{* *}$ Diferença Mínima Significativa. ${ }^{\text {ns }}$ Não significativo.

A atividade da RN dos genótipos estudados no presente trabalho não foi modulada positivamente pelas aplicações de piraclostrobina (Tabela 2). Isso pode ser explicado porque quando a disponibilidade de $\mathrm{N}$ no solo encontra-se em níveis adequados, a atividade enzimática da RN pode ser otimizada (OLIVEIRA et al., 2013), mascarando assim o efeito da piraclostrobina sobre essa enzima na cultura do milho. Resultados semelhantes foram observados por Schumacher et al. (2017) em hídridos de milho e para Martinazzo et al. (2016) em que as aplicações de piraclostrobina não influenciaram na atividade da redutase do nitrato em plantas de tomateiro cv. Micro-Tom.

Em contrapartida, Barbosa et al. (2011) observaram incremento médio de $17,5 \%$ na atividade da enzima redutase do nitrato a cada $30 \mathrm{~kg}$ de $\mathrm{N}$ adicionado ao solo, associado a aplicação de estrobilurinas na cultura do milho. Os mesmos autores relatam que o incremento no 
metabolismo do nitrogênio ocasionado pelo aumento da atividade da enzima redutase do nitrato, auxilia na potencialização da produtividade de grãos em plantas de milho tratadas com piraclostrobina.

Diferentemente dos genótipos de milho estudados que não apresentaram aumentos significativos na atividade da enzima $\mathrm{RN}$, em outras culturas, como trigo, onde os efeitos da aplicação de estrobilurina são mais notórias, Koehle et al. (2002) encontraram incrementos maiores que $70 \%$ na atividade da enzima RN até três noites após a aplicação, quando comparado a testemunha. Fagan et al. (2010), avaliando a aplicação de estrobilurina na cultura da soja, observou que a piraclostrobina obteve incremento de até $87 \%$ e $68 \%$ em relação a testemunha.

No presente estudo, as aplicações de piraclostrobina não ocasionaram efeito sobre o ICF (Tabela 2), obtidos nos estádios fenológicos V6 e VT. O fato de não haver diferença entre os fatores analisados, tanto para o índice de clorofila foliar, quanto para atividade da $\mathrm{RN}$, indica que essas características possuem relação direta, como descrito por Booij et al. (2000) e Barbieri Junior et al. (2012), que afirmam que o teor de clorofila na folha pode ser utilizado para predizer o nível nutricional de nitrogênio $(\mathrm{N})$ em plantas, devido ao fato desse pigmento possuir $\mathrm{N}$ na sua estrutura.

$\mathrm{Na}$ cultura do feijoeiro, os níveis adequados de adubação e o alto teor de matéria orgânica do solo (maiores que $80 \%$ ), disponibilizam uma quantidade maior de nitrogênio à planta, o que contribui para mascarar o efeito fisiológico das estrobilurinas no aumento da assimilação do nitrogênio, refletindo também na não diferenciação do teor de clorofila nas folhas da cultura (KOZLOWSKI et al., 2009). Não foi observado o efeito da aplicação de piraclostrobina para porcentagem de folhas senescentes (Tabela 2), havendo diferença apenas para o fator genótipo, no qual a Variedade AL Bandeirante apresentou maior porcentagem de senescência foliar, quando comparada aos demais genótipos.

LIMA et al. (2009), verificaram que o tratamento de sementes de milho com de piraclostrobina, associada a Metil Tiofanato, aumentou o índice de área foliar ativa (IAF) durante todo o desenvolvimento das plantas, demonstrando os efeitos aditivos dessa molécula sobre o retardamento da senescência foliar da cultura. Esse fato não foi observado no presente estudo, com o uso da associação piraclostrobina + epoxiconazol. Semelhante ao encontrado por Schumacher et al. (2017) em que a aplicação de piraclostrobina em hídridos de milho não afetou a porcentagem de folhas senescentes.

Para ferrugem polissora, mancha de cercospora, mancha de bipolaris e mancha branca, não houve interação significativa entre os fatores analisados, para a AACPD (Tabela 3).

Tabela 3. Resumo da análise de variância, valores de $F^{(1)}$ para: blocos, genótipos $(G)$, aplicações $(A)$ e suas interações ( $G \times A)$ para os valores de AACPD de ferrugem polissora (Puccinia polysora), mancha de cercospora (Cercospora zeae-maydis) e mancha de bipolaris (Bipolaris maydis). Jataí - GO, 2015.

\begin{tabular}{ccccc}
\hline $\begin{array}{c}\text { Fontes de } \\
\text { variação }\end{array}$ & Ferrugem polissora & $\begin{array}{c}\text { Mancha de } \\
\text { cercospora }\end{array}$ & $\begin{array}{c}\text { Mancha de } \\
\text { bipolaris }\end{array}$ & Mancha branca $^{3}$ \\
\hline Blocos & $3,34^{*}$ & $1,06^{\text {ns }}$ & $2,41^{\text {ns }}$ & $0,42^{\text {ns }}$ \\
Genótipos (G) & $77,92^{*}$ & $23,91^{*}$ & $1,453^{\text {ns }}$ & $84,40^{*}$ \\
Aplicações (A) & $0,67^{\text {ns }}$ & $1,67^{\text {ns }}$ & $0,08^{\text {ns }}$ & $1,55^{\text {ns }}$ \\
G x A & $1,10^{\text {ns }}$ & $0,49^{\text {ns }}$ & $1,38^{\text {ns }}$ & $1,21^{\text {ns }}$ \\
\hline${ }^{2}$ CV (\%) & 55,05 & 18,78 & 64,10 & 24,12 \\
\hline
\end{tabular}

*Médias seguidas pela mesma letra na coluna, não diferem entre si pelo teste Tukey $(P>0,05)$. ${ }^{* *}$ Diferença Mínima Significativa. ${ }^{\text {ns }}$ Não significativo.

Observa-se que para AACPD de ferrugem polissora e mancha de cercospora, houve diferença entre o fator genótipo, no qual a Variedade AL Bandeirante apresentou maior suscetibilidade a doenças quando comparada aos
Híbridos (Tabela 4), o que concorda com a classificação (mediamente suscetível) desse genótipo em relação ao comportamento de doenças (CRUZ et al., 2013). Para o Híbrido 1, não há informações sobre o comportamento em 
relação a doenças, porém, no presente estudo, esse genótipo apresentou comportamento semelhante ao Híbrido 2, que é classificado como mediamente tolerante (ferrugem polissora) e mediamente resistente (mancha de cercospora).

Com relação ao fator genótipo houve um comportamento inesperado para mancha branca, no qual o Híbrido 2 teve a maior AACPD, apesar de sua classificação como mediamente tolerante, e a Variedade AL Bandeirante teve valor menor que este genótipo e, no entanto, é classificada como mediamente suscetível (CRUZ et al., 2013). O Híbrido 1 , o qual não existem informações sobre o comportamento em relação a essa doença, apresentou a menor AACPD.

As condições edafoclimáticas do presente estudo, onde a precipitação acumulada foi de $439,0 \mathrm{~mm}$ com chuvas frequentes até o início do mês de maio, umidade relativa do ar (UR) diária em torno de $76,0 \%$, com temperatura média de
$24{ }^{\circ} \mathrm{C}$ (INMET, 2015), favoreceram o surgimento de ferrugem polissora, mancha de cercospora, mancha de bipolaris e mancha branca, e observase que independente da época de aplicação, não houve efeito da molécula de piraclostrobina no controle dessas doenças.

Jardine e Laca-Buendía (2009), Donato e Bonaldo (2013), ao conduzirem experimentos de segunda safra observaram diferença entre as aplicações de fungicidas testados para ferrugem polissora, sendo as melhores respostas obtida pela aplicação de piraclostrobina. Em relação a mancha de cercospora, os mesmos autores encontraram efeito no controle da aplicação de piraclostrobina, o que não ocorreu no presente estudo. Tal fato pode estar relacionado à baixa severidade da doença encontrada nas condições de cultivo do período.

Tabela 4. Valores médios referentes a área abaixo da curva de progresso da doença (AACPD) para ferrugem polissora, mancha de cercospora, mancha de bipolaris e mancha branca. Jataí - GO, 2015.

\begin{tabular}{lcccc}
\hline Tratamentos & $\begin{array}{c}\text { Ferrugem } \\
\text { polissora }\end{array}$ & $\begin{array}{c}\text { Mancha de } \\
\text { cercospora }\end{array}$ & $\begin{array}{c}\text { Mancha de } \\
\text { bipolaris }\end{array}$ & Mancha branca \\
\hline Genótipos (G) & & & & \\
Híbrido 1 & $137,92 \mathrm{a}^{*}$ & $28,41 \mathrm{a}$ & $17,77^{\mathrm{ns}}$ & $96,76 \mathrm{c}$ \\
Híbrido 2 & $144,88 \mathrm{a}$ & $14,21 \mathrm{a}$ & 12,94 & $985,02 \mathrm{~b}$ \\
Variedade & $1138,00 \mathrm{~b}$ & $110,90 \mathrm{~b}$ & 12,89 & $605,32 \mathrm{a}$ \\
\hline DMS $^{* *}$ & 226,28 & 24,96 & 7,30 & 198,41 \\
\hline Aplicações (A) & & & & \\
Aplic. 1 & $551,04^{\mathrm{ns}}$ & $75,04^{\mathrm{ns}}$ & $13,78^{\mathrm{ns}}$ & $532,70^{\mathrm{ns}}$ \\
Aplic. 2 & 416,69 & 27,45 & 15,57 & 666,27 \\
Aplic. 3 & 431,80 & 63,12 & 14,20 & 477,62 \\
Testemunha & 494,87 & 39,10 & 14,58 & 572,89 \\
\hline DMS & 288,04 & 31,86 & 9,30 & 252,56 \\
\hline 1. & & & & \\
\hline
\end{tabular}

${ }^{1} \mathrm{~F}$ calculado. ${ }^{*}$ Significativo a 5\%. ${ }^{\text {ns }}$ não significativo. ${ }^{2}$ Transformação: $\left.\log (\mathrm{Y}+\mathrm{k})\right)$, onde $\mathrm{k}=10 .{ }^{3}$ Transformação: raiz (Y).

Segundo Brito et al. (2013), aplicação de fungicida foi eficiente no controle de doenças foliares e na redução da incidência de grãos ardidos, além de proporcionar $12 \%$ de aumento na produtividade de grãos em relação à do tratamento controle. Além disso, a Cercosporiose causou maior redução de produtividade quando ocorreu mais precocemente no ambiente.

Os fungicidas do grupo químico das estrobilurinas demonstraram maior eficiência no controle de mancha branca quando comparados aos tratamentos com outros grupos químicos e sem aplicação de fungicida (JARDINE; LACABUENDÍA, 2009; DUARTE et al., 2009; COSTA et al., 2012b). Nas condições do presente estudo, não houve controle da mancha branca pelas épocas de aplicações de piraclostrobina (78 g i.a. $\left.\mathrm{ha}^{-1}\right)$, quando comparada a testemunha. Para Costa et al. (2011) estudando fungicidas de diferentes grupos químicos, as estrobilurinas apresentam elevada eficiência no controle da mancha branca do milho. Os fungicidas triazóis, carbendazim e os antiobióticos oxitetraciclina e kasugamicina apresentaram baixa eficiência no controle da doença. Schumacher et al., (2017) não observaram efeitos benéficos ou deletérios do uso de piraclostrobina (estrobilurina) aplicada em diferentes épocas e combinações de 
aplicação sobre dois híbridos simples de milho cultivados na safra de verão em condições de baixa severidade de mancha branca e ferrugem polissora.

Brito et al. (2008) ao avaliarem a severidade de mancha de cercospora em diferentes híbridos de milho cultivados em duas épocas de semeadura, observaram que os híbridos classificados como mediamente suscetíveis e mediamente resistentes mudaram de comportamento em relação a doença, em função da época em que foram semeados, fato que ocorreu com os genótipos Variedade AL Bandeirante e Híbrido 2, para mancha branca no presente trabalho.

De maneira geral, o desenvolvimento dessas doenças foi favorecido pelas condições climáticas durante período de condução do experimento, que apresentou temperaturas noturnas amenas (em média $16{ }^{\circ} \mathrm{C}$ ), e temperaturas mais elevadas durante o dia (30 ${ }^{\circ} \mathrm{C}$ ), além da umidade relativa do ar em torno de $77 \%$. A mancha de bipolaris ocorre em praticamente todo o território brasileiro, mas em baixa e média severidade (PINTO et al., 2006; GRIGOLLI, 2013), o que pode ser observado quando se compara a AACPD desta doença com as demais doenças avaliadas nesse estudo.

Não houve interação entre os fatores para as características de número de fileiras de grãos por espiga, número de grãos por fileira, massa de mil grãos e produtividade. Para as variáveis número de fileiras de grãos por espiga, massa de mil grãos e produtividade houve significância para as médias do fator genótipo (Tabela 5).

Tabela 5. Resumo da análise de variância, valores de $F^{(1)}$ para: blocos, genótipos (G), aplicações (A) e suas interações ( $G \times A)$ para os componentes de produção: número de fileiras de grãos por espiga (NF), número de grãos por fileira (NGF), massa de mil grãos (MMG) e produtividade (Prod.). Jataí - GO, 2015.

\begin{tabular}{lcclc}
\hline Fonte de variação & $\mathbf{N F}$ & NGF & MMG (g) & Prod. $\left(\mathbf{k g ~ h a}^{-\mathbf{1}}\right)$ \\
\hline Blocos & $40,91^{*}$ & $4,44^{*}$ & $0,89^{\text {ns }}$ & $7,25^{*}$ \\
Genótipos (G) & $15,80^{*}$ & $5,95^{*}$ & $54,18^{*}$ & $82,33^{*}$ \\
Aplicações (A) & $0,55^{\text {ns }}$ & $0,45^{\text {ns }}$ & $0,93^{\text {ns }}$ & $1,35^{\text {ns }}$ \\
G x A & $0,55^{\text {ns }}$ & $1,11^{\text {ns }}$ & $1,13^{\text {ns }}$ & $1,98^{\text {ns }}$ \\
\hline CV (\%) & 7,31 & 6,34 & 4,69 & 9,75 \\
\hline
\end{tabular}

*Médias seguidas pela mesma letra na coluna, não diferem entre si $(p>0,05)$ pelo teste Tukey. ${ }^{* *}$ Diferença Mínima Significativa. ${ }^{\text {ns }}$ Não significativo

Para o componente NF, os Híbridos 1 e 2 apresentaram os maiores números de fileiras de grãos por espiga, diferindo da Variedade $\mathrm{AL}$ Bandeirante (Tabela 6). Lopes et al. (2007) demonstraram que a seleção de espigas com maior número de grãos e maior massa de 1000 grãos tem efeito direto sobre o aumento do peso de grãos por espiga em híbridos simples de milho; Balbinot Jr. et al. (2005), descrevem que o número de grãos por fileiras e o peso de 100 grãos foram os dois componentes que mais influenciaram a produtividade. A Variedade AL Bandeirante apresentou menor número de fileira de grãos, podendo este ser um fator que contribuiu para uma menor produtividade desse genótipo, quando comparado aos demais. 
Tabela 6. Valores médios referentes à número de fileiras por espiga (NF), número de grãos por fileira (NGF), massa de mil grãos (MMG) e produtividade (Prod.) Jataí - GO, 2015

\begin{tabular}{lcccc}
\hline Tratamentos & NF & NGF & MMG (g) & Prod.(kg ha ${ }^{-1}$ ) \\
\hline Genótipos (G) & & & & \\
Híbrido 1 & $14,65 \mathrm{a}^{*}$ & $36,53 \mathrm{a}$ & $281,67 \mathrm{c}$ & $8244,81 \mathrm{a}$ \\
Híbrido 2 & $14,86 \mathrm{a}$ & $34,28 \mathrm{~b}$ & $317,77 \mathrm{~b}$ & $8629,81 \mathrm{a}$ \\
Variedade & $12,98 \mathrm{~b}$ & $34,11 \mathrm{~b}$ & $334,16 \mathrm{a}$ & $5587,96 \mathrm{~b}$ \\
\hline DMS $^{* *}$ & 0,89 & 1,92 & 12,66 & 633,66 \\
\hline Aplicações (A) & & & & \\
Aplic. 1 & $14,23^{\text {ns }}$ & $34,45^{\text {ns }}$ & $313,84^{\text {ns }}$ & $7330,61^{\text {ns }}$ \\
Aplic. 2 & 14,45 & 35,21 & 314,48 & 7338,51 \\
Aplic. 3 & 14,01 & 34,80 & 310,92 & 7848,39 \\
Testemunha & 13,97 & 35,43 & 305,57 & 7432,59 \\
\hline DMS $^{* *}$ & 1,14 & 2,44 & 16,12 & 803,60 \\
\hline
\end{tabular}

*Médias seguidas pela mesma letra não diferem entre si na coluna $(p>0,05)$ pelo teste Tukey. ${ }^{* *}$ Diferença Mínima Significativa. ${ }^{\text {ns }}$ Não significativo.

A ausência de efeito da aplicação de estrobilurina sobre o NF e o NGF, assim como no presente trabalho, é o observado por outros autores, que afirmam que a época de aplicação e as diferentes classes de estrobilurinas, não interferem nessas características da espiga do milho (HENRIQUES et al., 2014).

Conforme Venâncio et al. (2003), a maximização da eficiência fotossintética ocasionada pela aplicação de piraclostrobina tem efeito direto na translocação dos fotoassimilados para a formação de grãos e outros fatores de rendimento, no entanto, no presente trabalho não foi observado alterações nos componentes de produção ocasionadas pelas aplicações de piraclostrobina.

A MMG não foi significativamente alterada pela aplicação de piraclostrobina onde a testemunha obteve MMG de $305,57 \mathrm{~g}$, e as aplicações 1, 2 e 3 obtiveram MMG de 313,84 g, $314,48 \mathrm{~g}$ e $310,92 \mathrm{~g}$ respectivamente. Resultados semelhantes também foram descritos por Ecco et al. (2014), ao avaliarem híbridos de milho submetidos a aplicação de piraclostrobina + epoxiconazol, cultivados em segunda safra, não encontraram interação entre a aplicação de piraclostobrina e híbridos de milho, tanto pra MMG quanto para produtividade, havendo diferença apenas para fator híbrido. Jardine e Laca-buendía, (2009) avaliando diferentes formulações de fungicidas, incluindo epoxiconazol + piraclostrobina, aplicados em dois híbridos cultivados em segunda safra também não observaram diferença significativa entre os tratamentos testados para MMG.
Plantas de milho cultivadas em segunda safra submetidas à aplicação de estrobilurina demonstraram variação nos efeitos de produtividade de grãos, que hora tem incremento de produção, hora não apresentam efeito, e isso tem variado de acordo com o ano agrícola (DONATO; BONALDO, 2013).

Algumas cultivares de milho apresentaram decréscimo de produtividade quando tratadas com estrobilurinas, e isso ocorre, possivelmente, pela ação dessas moléculas sobre a inibição enzima ACC sintase, que é responsável pela síntese de etileno na planta, e pelo desenvolvimento das espigas de milho (COSTA et al., 2012a; BELOW et al., 2009). No presente estudo não houve efeito benéfico da aplicação de piraclostrobina sobre a produtividade de grãos do milho, porém não houve efeito deletério na produtividade de nenhum genótipo estudado.

\section{Conclusões}

A aplicação de piraclostrobina não interfere na fisiologia, desenvolvimento e produtividade de grãos das plantas de milho cultivados em segunda safra e não houve diferença significativa no controle das doenças ferrugem polissora, mancha de cercospora, mancha de bipolares e mancha branca pela aplicação de piraclostrobina nos genótipos estudados.

\section{Referências}

AGROCERES. Guia Agroceres de Sanidade, São Paulo, 1993. 56p. 
AMARO, A. C. E.; RAMOS, A. R. P.; MACEDO, A. C.; ONO, E. O.; RODRIGUES, J. D. Effects of the fungicides azoxystrobin, pyraclostrobin and boscalid on the physiology of Japanese cucumber, Scientia Horticultura, v. 228, p.66-75, 2018.

ANDRZEJEWSK, J. H. S.; BELLETTINI, S.; BELLETTINI, N. M. T.; OLIVEIRA, E. M. B. B. Influência do desfolhamento nos componentes de produção do milho. Brazilian Journal of Development, v. 6, n. 7, p. 52334-52353, 2020.

BARBIERI JUNIOR, É. R.; ROBERTO O. P.; SILVA, R. V. M. M.; RIBEIRO, R. C.; MORENZ, M. J. F. Um novo clorofilômetro para estimar os teores de clorofila em folhas do capim Tifton 85. Ciência Rural, v. 42, n. 12, p. 2242-2245, 2012.

BARBOSA, K. A.; FAGAN, E. B.; CASAROLI, D.; CANEDO, S. C.; TEIXEIRA, W. F. Aplicação de estrobilurina na cultura do milho: alterações fisiológicas e bromatológicas. Cerrado Agrociências, v. 2, p. 20-29, 2011. http://dx.doi.org/10.1590/S000687052010000400001

BELOW, F. E.; DUNCAN, K. A.; URIBELARREA, M.; RUYLE, T. B. Occurrence and proposed cause of hollow husk in maize. Agronomy Journal, v. 101, p. 237-242, 2009. http://dx.doi:10.2134/agroni2008.0158N

BOOIJ, R.; VALENZUELA, J. L.; AGUILERA, C. Determination of crop nitrogen status using noninvasive methods. In: HAVERKORT, A. J.; MACKERRON, D. K. L. (Eds.). Management of nitrogen and water inpotato production. The Netherlands: Wageningen Pers. Wageningen Pers, 2000. p.72-82.

BRASIL. Ministério da Agricultura, Pecuária e Abastecimento. Secretaria de Defesa Agropecuária. Regras para análise de sementes. Brasília: Mapa/ACS, 2009. 399 p.

BRITO, A. H.; VON PINHO, R. G.; SOUZA FILHO, A. X.; ALTOÉ, T. F. Avaliação da severidade da cercosporiose e rendimento de grãos em híbridos comerciais de milho. Revista Brasileira de Milho e Sorgo, Lavras, v. 7, n. 1, p. 19-31, 2008.

BRITO, A. H.; VON PINHO, R. G.; PEREIRA, J. L. A. R.; BALESTRE, $M$. Controle químico da cercosporiose, mancha-branca e dos grãos ardidos em milho. Revista Ceres [online], v. 60, n. 5, 2013.

CAMPBELL, C. L.; MADDEN, L. V. Introduction to plant disease epidemiology. New York: Wiley, 1990. $532 \mathrm{p}$.

CONAB. Acompanhamento da safra brasileira: grãos, - décimo segundo levantamento, setembro de 2019 - v. 6, n. 12 - Safra 2018/19. Disponível em: http://www.conab.gov.br. Acesso em: set. 2020.

COSTA, D. F.; VIEIRA, B. S.; LOPES, E. A.; MOREIRA, L. C. B. Aplicação de fungicidas no controle de doenças foliares na cultura do milho. Revista Brasileira de Milho e Sorgo, v. 11, n. 1, p. 98-105, 2012b.

COSTA, R. V.; COTA, L. V.; SILVA, D. D.; LANZA, F. E. Recomendações para o controle químico da mancha branca do milho. Circular Técnica, v. 167, p. 1-6, 2011.

COSTA, R. V.; COTA, L. V.; SILVA D. D.; MEIRELLES, W. F.; LANZA, F. E. Viabilidade técnica e econômica da aplicação de estrobilurinas em milho. Tropical Plant Pathology, v. 37, n. 4, p. 246-254,

2012a.

http://dx.doi.org/10.1590/S1982$\underline{56762012000400003 .}$.

CRUZ, J. C.; FILHO, I. A. P.; QUEIROZ, L. R. Milhocultivares para 2013/2014. Sete Lagoas: Embrapa Milho e Sorgo, 2013. Disponível em http://www.cnpms.embrapa.br/milho/cultivares. Acesso em: jul. 2016.

DONATO, V. M. T. S.; ANDRADE, A. G. de.; SOUZA, E. de S.; FRANÇA, J. G. E. de.; e MACIEL, G. A. Atividade enzimática em variedades de cana-deaçúcar cultivadas in vitro sob diferentes níveis de nitrogênio. Pesquisa Agropecuária Brasileira. Brasília, v. 39, n. 11, p. 1087-1093, 2004.

DUARTE, R. P.; JULIATTI, F. C.; FREITAS, P. T. Eficácia de diferentes fungicidas na cultura do milho. Bioscience Journal, Uberlândia, v. 25, n. 4, p. 101-111, 2009.

ECCO, M.; ROSSET, J. S.; RAMPIM, L.; COSTA, A. C. T.; LANA, M. C.; STANGRLIN, J. R.; SARTO, M. V. $M$. Características agronômicas de híbridos de milho segunda safra submetidos à aplicação de 
fungicida. Revista Agrarian, Dourados, v. 7, n. 26, p. 504-510, 2014.

EMBRAPA. Centro Nacional de Pesquisa de Solos. Sistema brasileiro de classificação de solos. Rio de Janeiro: Embrapa Produção de Informação, 2009. 412 p.

FAGAN, E. B.; NETO, D. D.; VIVIAN, R.; FRANCO, R. B.; YEDA, M. P.; MASSIGNAM, L. F.; OLIVEIRA, R. F.; MARTINS, K. V. Efeito da aplicação de piraclostrobina na taxa fotossintética, respiração, atividade da enzima nitrato redutase, e produtividade de grãos de soja. Bragantia, Campinas, v. 69, n. 4, p. 771-777, 2010. http://dx.doi.org/10.1590/S0006-

\section{$\underline{87052010000400001 .}$.}

FERREIRA, D. F. Sisvar: a computer statistical analysis system. Ciência e Agrotecnologia, v. 35, n. 6, p. 1039-1042, 2010.

\section{GRIGOLLI, J. F. J. Doenças do milho safrinha.}

Tecnologia e produção: Milho safrinha e culturas de inverno. Mato Grosso do Sul: Fundação MS, 2013. p. 121-133.

HENRIQUES, M. J.; OLIVEIRA NETO, A. M.; GUERRA, N.; OLIVEIRA, N. C.; CAMACHO, L. R. S.; GONZATTO JUNIOR, O. A. G. Controle de helmintosporiose em milho com aplicação de fungicidas em diferentes épocas. Revista Ciências Exatas e da Terra e Ciências Agrárias, v. 9, n. 2, p. 45-57, 2014.

INMET. BDMEP - Banco de Dados Meteorológicos para Ensino e Pesquisa: Série Histórica - Dados Diários de 06/03/2015 a 30/07/2015 Estação: 83464. Jatai-GO, 2015. Disponível em: http://www.inmet.gov.br/portal/index.php?r=bd mep/bdmep. Acesso em: ago. 2015.

JARDINE, D. F.; LACA-BUENDÍA, J. P. Eficiência de fungicidas no controle de doenças foliares na cultura do milho. FAZU em Revista, n. 6, p. 11-52, 2009.

JAWORSKI, E. G. Nitrate reductase assay in intact plant tissues. Biochemical and Biophysical Research Communications, v. 43, n. 6, p. 12741279, 1971. https://doi.org/10.1016/S0006291X(71)80010-4.
KARAN, D.; MAGALHÃES, P. C. Eficiência nas cadeias produtivas e o abastecimento global. Salvador, 2014. 411 p.

KÖEHLE, H.; GROSSMANN, K.; JABS, T.; GERHARD, M.; KAISER, W.; GLAAB, J.; CONRATH, U.; SEEHAUS, K.; HERMS, S. Physiological effects of the strobilurin fungicide $\mathrm{F} 500$ on plants. Modern fungicides and antifungal compounds III, Andover: Agro Concept, p. 61-74, 2002.

KOZLOWSKI, L. A.; SIMÕES, D. F. M.; SOUZA, C. D.; TRENTO, M. Efeito fisiológico de estrobilurina $F$ $500^{\circ}$ no crescimento e rendimento do feijoeiro. Ciências Agrárias e Ambientais, v. 7, n. 1, p. 4154, 2009.

LIMA, A. S.; REFFATTI, T. N.; JUNCOS. M. C.; BURBULHAN, T.; MARTIKOSKI, L. Efeito fisiológico de fungicida Pyraclostrobin e tratamento de sementes na cultura do milho. Pesquisa Aplicada e Agrotecnologia, v. 2, n. 3, p. 115-120, 2009.

LOPES, S. J.; LÚCIO, A. D. C.; STORCK, L.; DAMO, H. P.; BRUM, B.; SANTOS, V. J. Relações de causa e efeito em espigas de milho relacionadas aos tipos de híbridos. Ciência Rural, v. 37, n. 6, p. 1536-1542, 2007. http://dx.doi.org/10.1590/S010384782007000600005.

MAGALHÃES, P. C.; DURÃES, F. O. M. Fisiologia da produção de milho. Sete Lagoas: Ministério da Agricultura, Pecuária e Abastecimento, 2006. 10p. (Circular Técnica; 76).

MARTINAZZO, G. E.; TESSARI, P. A.; TAMIRES, T. M.; POSSO, D. A.; SILVA GALDINO, A. C.; BACARIN, M. A. Efeito da aplicação de nitrogênio e de piraclostrobinaem plantas de tomateiro cultivar Micro-Tom, Revista Ceres, v. 63, n. 5, p. 676-682, 2016.

MEGURO, N. E.; MAGALHÃES, A. C. Atividade da redutase de nitrato em cultivares de café. Pesquisa Agropecuária Brasileira, v. 17, n. 12, p. 156-159, 1982.

MOTERLE, L. M.; SANTOS, R. F. Época de aplicação de fungicida na cultura do milho segunda safra. Colloquium Agrariae, v. 15, n. 2, p. 61-71, 2019. 
OLIVEIRA, L. R.; MIRANDA, G. V.; LIMA, R. O.; FRITSCHE-NETO, R.; GALVÃO, J. C. C. Eficiência na absorção e utilização de nitrogênio e atividade enzimática em genótipos de milho. Revista Ciência Agronômica, v. 44, n. 3, p. 614-621, 2013.

PINTO, N. F. J. A.; SANTOS, M. A. DOS; WRUCK, D. S. M. Principais doenças da cultura do milho. Informe Agropecuário: cultivo do milho no sistema de plantio direto, v. 27, n. 233, p. 7-12, 2006.

PURCINO, A. A. C.; MAGNAVACA, R.; MACHADO, A. T. Atividade da redutase do nitrato em genótipos antigos e modernos de milho, cultivados sob dois níveis de nitrogênio. Revista Brasileira de Fisiologia Vegetal, v. 6, n. 1, p. 4146, 1994.

RITCHIE, S. W.; HANWAY, J. J.; BENSON, G. O. How a corn plant develops. Ames: lowa State University of Science and Technology, 1993. 26 p. (Special report; 48).

SCHUMACHER, P. V.; ROSSATO, M.; COSTA NETTO, A. P.; D’ABADIA, A. C. A.; REIS, E. F. Resposta de híbridos de milho ao uso de piraclostrobina na ausência de doenças. Arquivos do Instituto Biológico, v. 84, p. 1-8, 2017.

VENÂNCIO, W. S.; RODRIGUES, M. A. T.; BEGLIOMINI, E.; SOUZA, N. L. Physiological effects of strobilurin fungicides on plants. Revisão Anual de Patologia de Plantas, v. 12, p. 317-341, 2003. 